\title{
PV system reactive power coordination with ULTC and shunt capacitors using grey wolf optimizer algorithm
}

\author{
Mogaligunta.Sankaraiah ${ }^{1}$, S.Suresh Reddy ${ }^{2}$, M.Vijaya Kumar ${ }^{3}$ \\ ${ }^{1}$ Electrical and Electronics Engineering, Research Scholar, JNTUA, India \\ ${ }^{2}$ Electrical and Electronics Engineering, Professor, N.B.K.R.I.S.T, Vidyanagar, India \\ ${ }^{3}$ Electrical and Electronics Engineering, Professor, JNTUA, India
}

\begin{tabular}{l} 
Article Info \\
\hline Article history: \\
Received Jul 2, 2019 \\
Revised Dec 30, 2019 \\
Accepted Jan 20, 2020 \\
\hline Keywords: \\
Grey wolf optimizer \\
Particle swarm optimization \\
Reactive power controlled \\
devices
\end{tabular}

devices

\begin{abstract}
The presence of PV systems increases rapidly in distribution systems to improve reliability and quality of supply. This will influence the performance of under load tap changing (ULTC) transformer and related reactive power devices. Therefore, many researchers are working on this area. This paper main objective is to reduce switching operations of reactive power devices (ULTC and Shunt capacitors) together with system power loss. Distribution system load and solar system power will predict one day in advance and grey wolf optimizer (GWO) algorithm proposed to solve the objective function. Reactive power of solar system is coordinated together with ULTC and shunt capacitors (SCs) with the aid of forecasted load. Distribution system losses and switching operations of ULTC and SCs converted into objective function in terms of cost. The proposed method is applied on practical 10KV system and the results are compared with conventional and particle swarm optimization (PSO) methods considering grid conditions.
\end{abstract}

Copyright $($ C 2020 Institute of Advanced Engineering and Science. All rights reserved.

\section{Corresponding Author:}

Mogaligunta Sankaraiah,

Department of Electrical and Electronics Engineering,

Research Scholar, JNTUA University,

Ananthapuramu, Andhra Pradesh, India.

Email: Ananthapuramu, Andhra Pradesh, India

\section{INTRODUCTION}

In general, most of the distribution systems are radial in nature and therefore stressed with voltage profile and losses [1]. The problems associated with conventional radial distribution systems are overcome with the presence of distributed generation (DG). Among DGs, solar power generation is the most powerful distri-buted generation [2]. The presence of DGs affecting performance of voltage controlled devices, in terms of increasing switching operations (SOs) and there by life of the devices [3]. In [4], it is reported that the switching operations of voltage controlled devices (VCDs) are increased more than three times due to the presence of DGs. In [5], it is reported that SOs increased more than two times with SCADA system. In [6], DGs and VCDs are coordinated using dynamic programming method. In [7], combined voltage control method used to control DGs and VCDs. In all these methods, the reactive power availability of DG not considered at the time of reactive power scheduling of VCDs.

In [8], voltage and reactive power coordinated with syn-chronous generator considered as a DG. Real power of DG was coordinated in an autonomous system by applying optimal power flow approach [9]. TRSQP method was proposed for DG coordi-nation with reactive power devices [10]. In [11], Asynchronous and synchronous generators were coordinated with reactive power devices. Adaptive programming method was proposed for coordi-nation of DG and reactive power devices [12]. 
In [13], dynamic programming method was proposed and in [14], PSO method was proposed for DG and reactive power devices coordination. In [15-18], many methods proposed like TRSQP, Adaptive voltage controlled, dynamic programming and improved search harmony for reactive power coordination among VCDs and DG. In [18], PSO method proposed for dispatchable DG reactive power coordination with VCDs. In [19], GWO method proposed for DFIG reactive power coordination with ULTC and SCs. These methods proposed for improving the life of VCDs by decreasing the switching operations as well as power loss of the system.

The methods proposed by many authors focused mainly on dispatchable DGs and importance given for non-dispatchable DGs especially for PV type of DG was very small. In this paper, PV system power is coordinated with reactive power control devices by using GWO algorithm to reduce the switching operations of reactive power control devices and power loss of the system.

\section{MODELING OF PV SYSTEM}

In distribution system planning and operation, it is very important to model PV system power on hourly basis. PV system power mainly depends on radiation, temperature and properties of materials used for the construction [20]. The power generated by PV system can be estimated by using a simple equation in terms of standard test conditions (STC) and normal operating cell temperature (NOCT). Mattei et al proposed (1) for solar module efficiency calculation [21].

$$
\begin{aligned}
& \eta_{s m}=\eta_{S C}\left(1-\beta_{S C P}\left(T_{S C T}-T_{S T C}\right)+\alpha \times \log G\right) \\
& T_{S C T}=T_{a m b}+\left(T_{N O C T}-20^{\circ} C\right) \times \frac{G}{800 \frac{w}{m^{2}}}
\end{aligned}
$$

Where $\eta_{s m}$ is the solar module efficiency at STC, $G$ is solar irradiance, $T_{S T C}$ is Temperature at STC, $T_{S C T}$ is solar cell temperature, $\beta_{S C P}$ is power temperature coefficient of solar cell, $\eta_{S C}$ is efficiency of solar cell, $T_{a m b}$ is ambient temperature, $\alpha$ is irradiation coefficient and $T_{\text {NOCT }}$ is the temperature at NOCT. as follows:

The power from solar module is important; therefore, (1) modified as power equation

$$
P_{s m}=\frac{G}{1000 \frac{w}{m^{2}}} \times P_{n s m} \times\left(1-\beta_{S C P}\left(T_{S C T}-T_{S T C}\right)\right)
$$

Where $P_{s m}$ is the power of solar module and $P_{n s m}$ is the nominal solar module power at STC. Using (3), the power of solar module estimated on hourly basis.

\section{PROBLEM FORMATION}

Where:

Single line diagram of solar connected grid system shown in Figure 1.

$\begin{array}{llll}E_{G V} & : \text { Grid Voltage } & E_{S V} & \text { : Sending end Voltage } \\ E_{P V} & : \text { PV system Voltage } & r: \text { Tap position } \\ Q_{S C} & : \text { Reactive power injected by Capacitors at sending end } & \\ Q_{S C} & : \text { Reactive power injected by Capacitors at receiving end } & \\ P_{G P} & : \text { Grid real power } & Q_{G P} & : \text { Grid reactive power } \\ P_{T R L} & : \text { Transmission line real power } & Q_{T R L} & : \text { Transmission line reactive power } \\ P_{P V} & : \text { PV system real power } & Q_{P V} & : \text { PV system reactive power } \\ P_{L P} & : \text { Load real power } & Q_{L P} & : \text { Load reactive power } \\ R_{T R L} & : \text { Transmission line resistance } & X_{T R L} & : \text { Transmission line reactance } \\ \delta & : \text { Sending end voltage angle. } & & \end{array}$




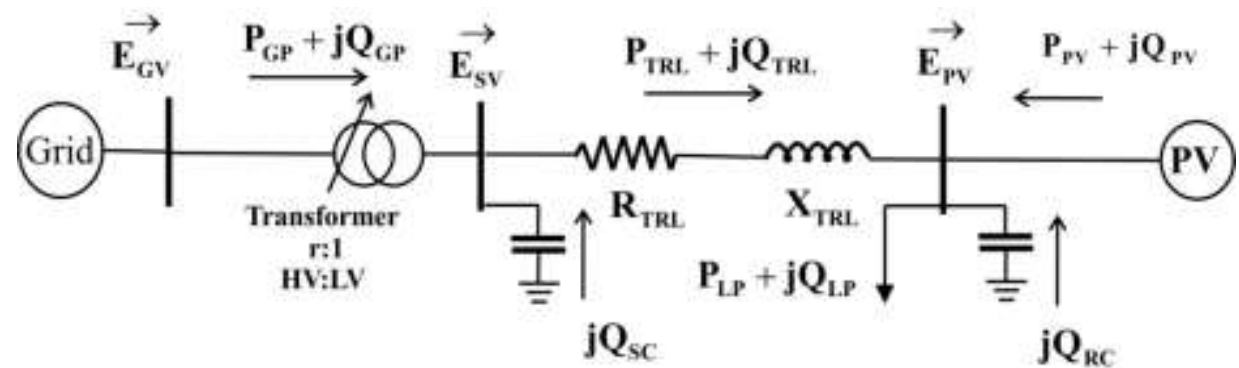

Figure 1. Single line diagram of PV system connected to grid

Distribution system power loss for every hour is calculated using the following formula:

$$
P_{\text {Loss }}^{h}=\left|\frac{E_{S V} \times \cos (\delta)+j E_{S V} \times \sin (\delta)-E_{P V}}{R_{T R L}+j X_{T R L}}\right|^{2} \times R_{T R L}
$$

The overall objective function consists of two terms, first one is power converted to cost function and second one is switching loss converted to cost function. Objective function of power loss written as power loss multiplied with cost of power loss, represented in (5).

$$
J_{1}=\sum_{h=1}^{24} C_{P} \times P_{\text {Loss }}^{h}
$$

Objective function of switching loss due to ULTC and shunt capacitors represented in (6).

$$
J_{2}=\sum_{h=1}^{24}\left(\begin{array}{l}
C_{1} \times\left|r^{h}-r^{h-1}\right|+C_{2} \times\left|K_{S C}^{h}-K_{S C}^{h-1}\right| \\
+C_{3} \times\left|K_{F C}^{h}-K_{F C}^{h-1}\right|
\end{array}\right)
$$

The overall objective function can be written as:

$$
J=\min \left(J_{1}+J_{2}\right)
$$

Where:

$h$ : Number of hours

$C_{P}:$ Power loss cost function

$C_{1}:$ Cost function of tap variations

$C_{2}$ : Cost function of source capacitors variations

$C_{3}$ : Cost function of feeder capacitors variations

$K_{S C}^{h}$ : Number of source capacitors connected at h

$K_{S C}^{h-1}$ : Number of source capacitors connected at h-1

$K_{F C}^{h}:$ Number of feeder capacitors connected at $\mathrm{h}$

$K_{F C}^{h-1}$ : Number of source capacitors connected at h-1

Equations (8) to (14) are the constraints for objective function. Power constraints:

$$
\begin{aligned}
& P_{P V}-P_{L P}=P_{L o s s} \\
& Q_{P V}-Q_{L P}=Q_{L o s s} \\
& Q_{P V}^{\min } \leq Q_{P V} \leq Q_{P V}^{\operatorname{mxx}}
\end{aligned}
$$

Voltage, ULTC and shunt capacitors constraints: 


$$
\begin{aligned}
& E^{\min } \leq E \leq E^{\max } \\
& r^{\min } \leq r \leq r^{\max } \\
& K_{S C}^{\min } \leq K_{S C} \leq K_{S C}^{\max } \\
& K_{F C}^{\min } \leq K_{F C} \leq K_{F C}^{\max }
\end{aligned}
$$

\section{GWO ALGORITHM}

The multi objective function formulated and indicated in equa-tion (7) requires qualitative algorithm for generating the best result among different combinations. Too many algorithms are available like evolutionary based, SI based and physics based. Among evo-lutionary Genetic algorithm is most powerful and best algorithm proposed in 1992 [22-23]. The remaining some of the important algorithms under this group are differential evolution, evolutionary programming and strategy [24-25]. Some of the important physics based algorithms are GLSA [26], BBBC [27], GSA [28], and ACROA [29], in the SI group the important algorithms are terminate algorithm (TA) [30], Bee collecting pollen algorithm (BCPA) [31], Monkey search algorithm (MS) [32] and Wasp swarm algorithm (WSA) [33].

The algorithms listed above inspired by exploration and hunting behaviors, there is no algorithm which apes both the behaviors in leadership hierarchy, therefore this paper proposes GWO algorithm [34] for solving multi objective function, which ape hunting, exploration in a leadership hierarchical. This algorithm follows three major steps, first step involves look, pursue and move towards the quarry. Second step involves chase, surround and hassle the quarry. Third step involves hitting the quarry this section, it is explained the results of research and at the same time is given the comprehensive discussion.

\subsection{Proposed method implementation}

Implementation of GWO algorithm is as follows:

Step 1: Set all initial conditions.

The values of cost weighting factors $C_{P}, C_{1}, C_{2}$ and $C_{3}$, number of searching agents, maximum iterations, number of parameters to be tuned and their minimum and maximum limits, initial values for alpha, beta and delta, forecasted load.

Step 2: Calculate power loss in the system for first hour

Run Backward/Forward algorithm with initial values and calculate power loss and voltages at all the buses in the system.

Step 3: Calculate Objective function value of each search agent

With obtained power loss in step 2, with initial values of parameters and their cost weighting factors calculate objective function value of each search agent.

Step 4: Update voltages

Run Backward/Forward algorithm with updated search agents and update all buses voltages.

Step 5: Fitness function calculation

Calculate the fitness function value using (2).

Step 6: Update alpha, beta and delta

If fitness value is less than alpha score then update alpha with alpha score is equal to fitness, if fitness is greater than alpha score but less than beta score update beta with beta score is equal to fitness, if fitness is greater than alpha score and beta score but less than delta score then update delta with delta score is equal to fitness value.

Step 7: Update positions of search agents including omega

Generate two random numbers $r_{n 1}, r_{n 2}$ and then evaluate matrix $B_{1}$ and $F_{1}$ using the following (15-16), update the distance of each search agent with the help of equations 17-20.

$$
\begin{aligned}
& B_{1}=2 a_{1} r_{n 1}-a_{1} \\
& F_{1}=2 r_{n 2} \\
& D_{\alpha}=F_{1} P_{\alpha}-\text { Best }_{\alpha}
\end{aligned}
$$




$$
\begin{aligned}
& D_{\beta}=F_{1} P_{\beta}-\text { Best }_{\alpha} \\
& D_{\delta}=F_{1} P_{\delta}-\text { Best }_{\alpha} \\
& D_{\omega}=F_{1} P_{\omega}-\text { Best }_{\alpha}
\end{aligned}
$$

Where $\mathrm{P}$ indicates present position, $\mathrm{D}$ indicates distance and Best indicates present best position.

Step 8: Update parameters to be tuned

Based on the positions of search agents update the parameters which are to be determined.

Step 9: Update voltages

Run Backward/Forward algorithm with updated search agents and update all buses voltages.

Step10: Repeat steps 2 to 9 for remaining hours

In this paper the total time is spatter into 24 hours, therefore, repeat the same procedure using steps 2 to 9.

Step11: Stopping criteria

If iterations are completed, then stop and display best results in every hour.

\section{TEST SYSTEM AND RESULT}

Figure 2 represents $10 \mathrm{kv}$ test system with 16 buses. Figures 3 to 5 illustrates forecasted load over 24 hours on each bus. Figure 6 indicates forecasted solar power using (3) for 24 hours. Load variations of all the nodes and output power of solar system is predetermined one day in advance. The effectiveness of the proposed method tested on $10 \mathrm{kv}$ practical system by placing solar system at different locations randomly. Depending upon the location of solar system, results listed in three cases.

In first case solar system placed at bus 5 on feeder 1 , in second case solar sys-tem placed at bus 8 on feeder 2 and in third case at bus 14 on feeder 3. Figures 6 to 13 indicates switching operations of reactive power control devices with solar system located at bus 5 on feeder 1. In Figure 6, ULTC changing tap position by 4 times in conventional method where reactive power of solar system is not considered. In Figure 7, ULTC tap variations are reduced to 2 times with PSO method and 1 time with GWO method where the reactive power of solar system is coordinated. Similarly, switching operations of shunt capacitors at source are 10, 0 and 0 ; feeder 1 capacitors are 5, 7 and 0 ; feeder 2 capacitors are 4, 4 and 3 with conventional, PSO and GWO methods respectively. Table 1, Table 2 and Table 3 indicates system power loss and switching operations of ULTC and shunt capacitors with solar system located at 5 (case 1), at 8 (case 2) and at 14 (case 3) respectively. Equations 21 and 22 used for the calculation of power loss, switching operational cost (SOC) and total cost in tables 1 to 3.

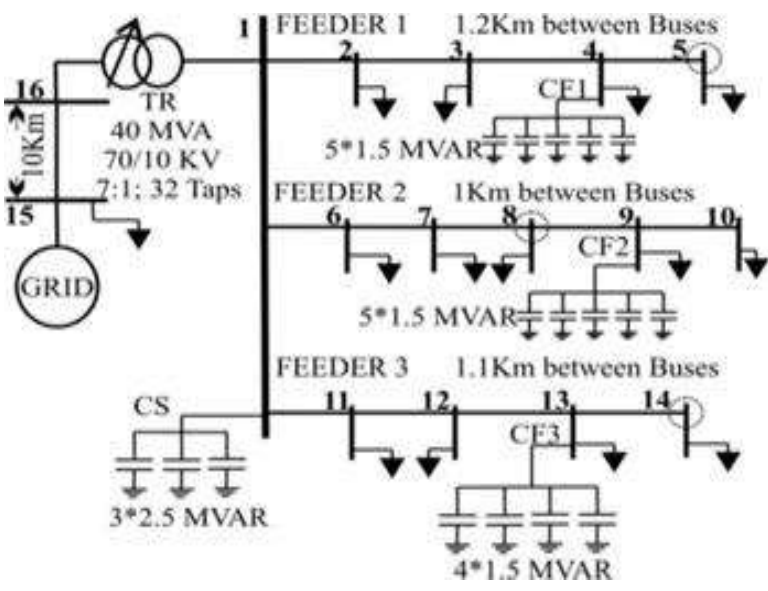

Figure 2. Feeder 1 loads variations (active power)

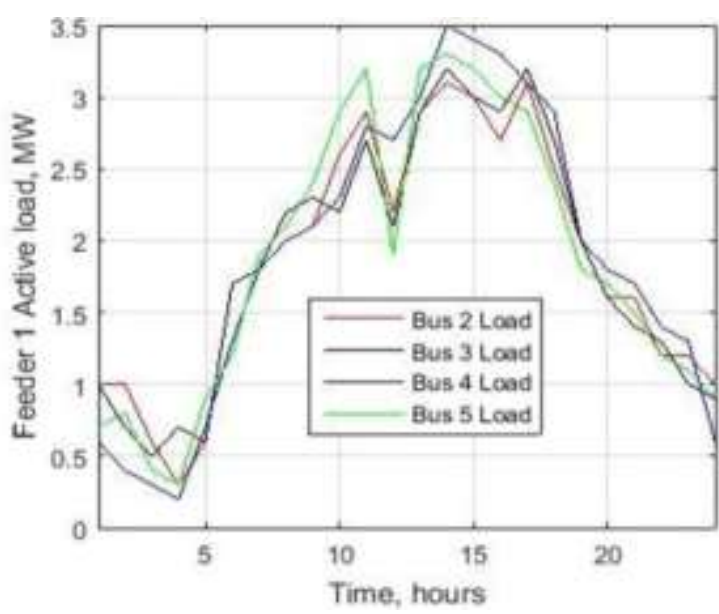

Figure 3. Feeder 2 loads variations (active power) 


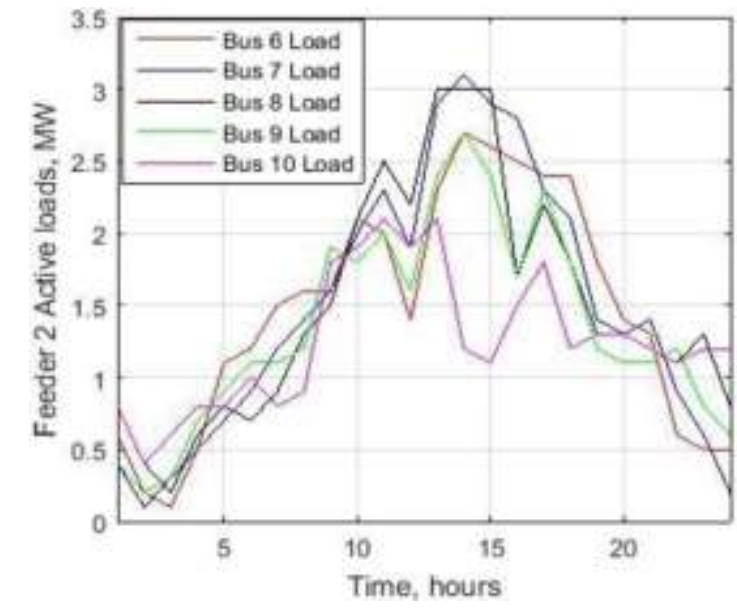

Figure 4. Feeder 3 loads variations (active power)

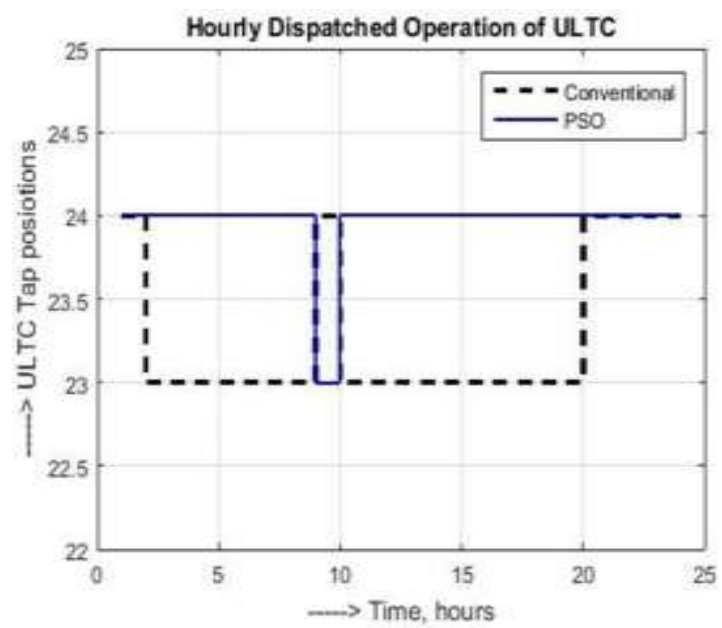

Figure 6. ULTC scheduled operation for 24 hours with conventional and PSO methods

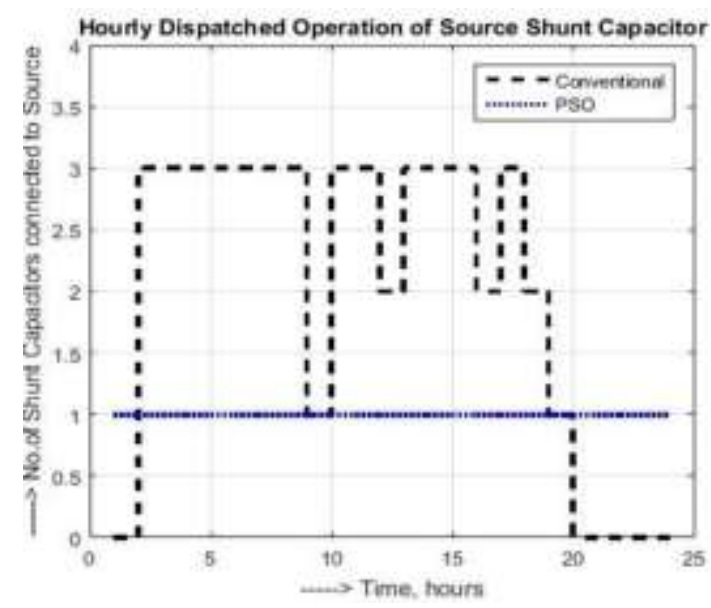

Figure 8. Source Capacitors scheduled operation for 24 hours with conventional and PSO methods

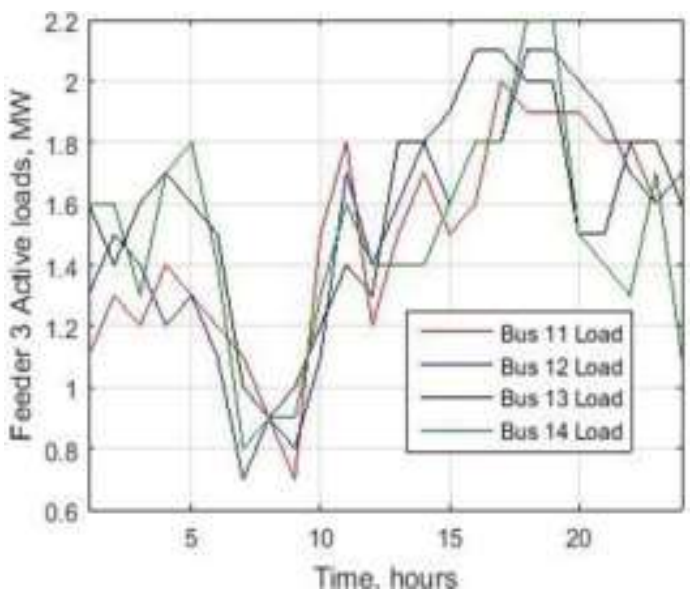

Figure 5. Feeder 2 loads variations (active power)

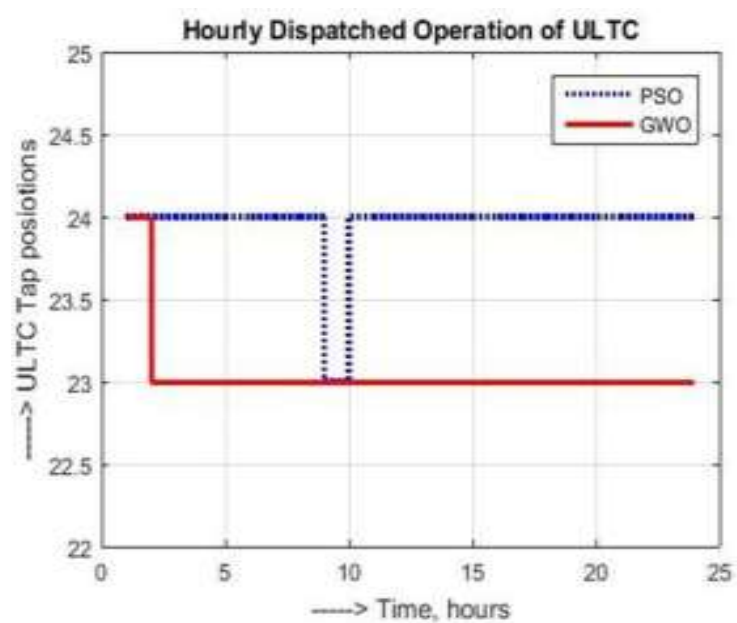

Figure 7. ULTC scheduled operation for 24 hours with PSO and GWO methods

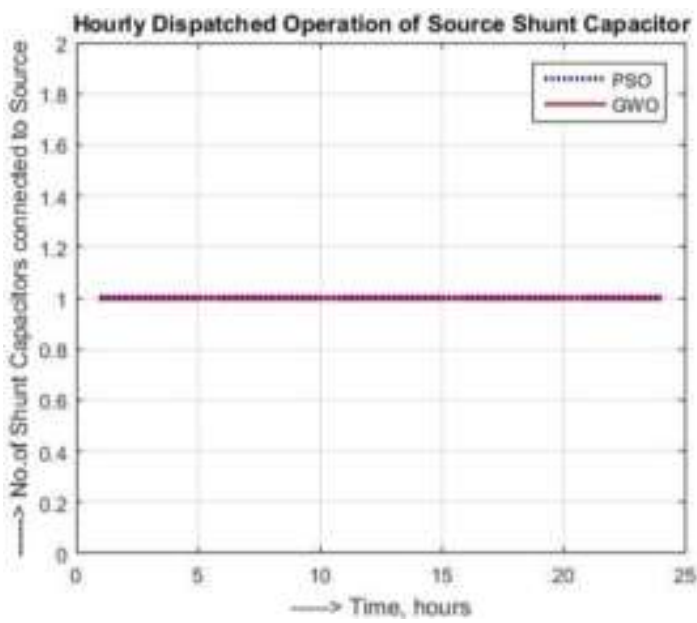

Figure 9. Source Capacitors scheduled operation for 24 hours with PSO and GWO methods 


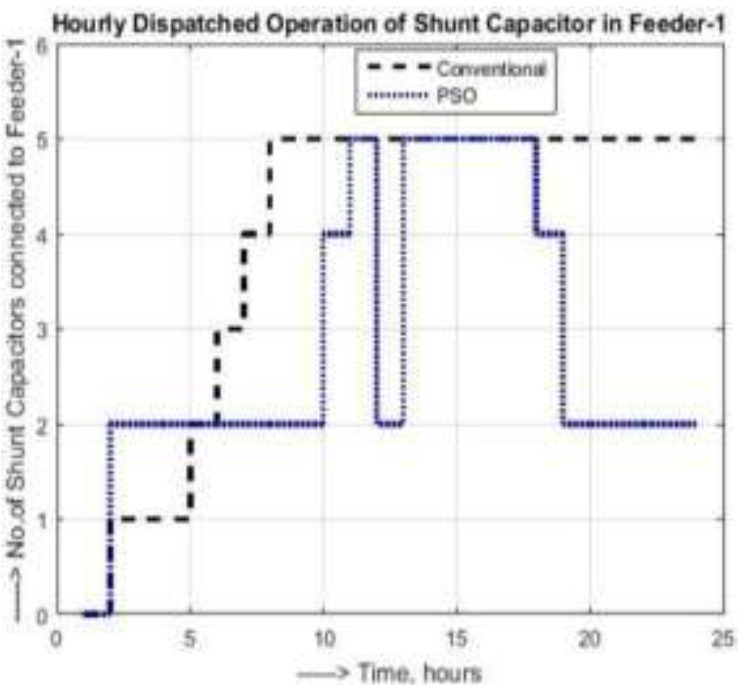

Figure 10. Feeder 1 Capacitors scheduled operation for 24 hours with conventional and PSO methods

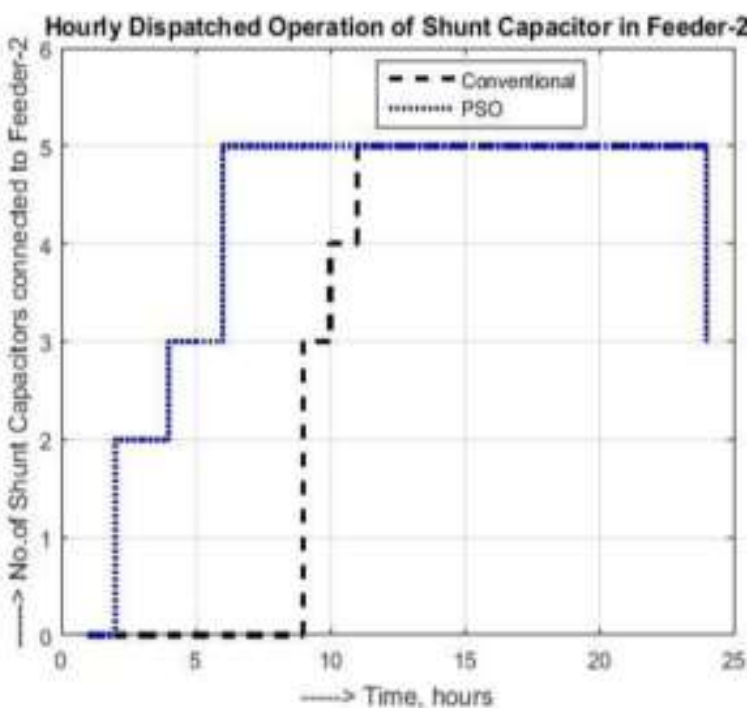

Figure 12. Feeder 2 Capacitors scheduled operation for 24 hours with conventional and PSO methods

Table $1.10 \mathrm{kv}$ practical system results for Case 1

\begin{tabular}{|c|c|c|c|c|}
\hline \multicolumn{5}{|c|}{ DG at Bus 5 on Feeder 1} \\
\hline Control N & thods & $\mathrm{CON}$ & PSO & GWO \\
\hline \multicolumn{2}{|c|}{ Power loss (MWh) } & 12.89 & 12.14 & 11.41 \\
\hline Number of & ULTC & 4 & 2 & 1 \\
\hline Switching & $\mathrm{SC}$ & 10 & 0 & 0 \\
\hline onerations & $\mathrm{F} 1 \mathrm{C}$ & 5 & 7 & 1 \\
\hline operations & $\mathrm{F} 2 \mathrm{C}$ & 3 & 4 & 1 \\
\hline & $\mathrm{F} 3 \mathrm{C}$ & 2 & 1 & 7 \\
\hline \multicolumn{2}{|c|}{ Power loss (\$) } & 1031.84 & 971.464 & 913.384 \\
\hline \multirow{2}{*}{\multicolumn{2}{|c|}{$\begin{array}{c}\operatorname{SSVF}(\%) \\
\operatorname{SOC}(\$)\end{array}$}} & 23.37 & 14.75 & 11.07 \\
\hline & & 1320 & 640 & 440 \\
\hline \multicolumn{2}{|c|}{ Total Cost (\$) } & 2351.84 & 1611.46 & 1353.38 \\
\hline
\end{tabular}

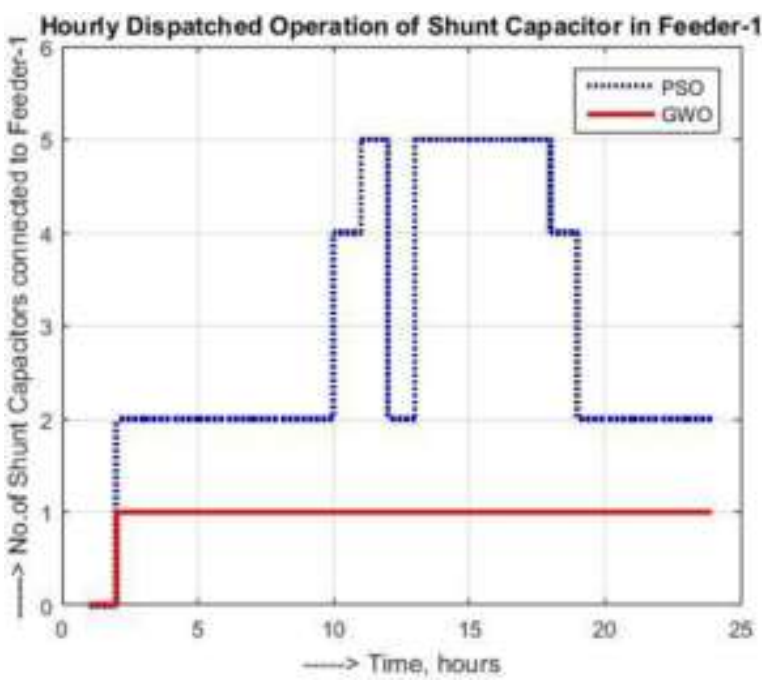

Figure 11. Feeder 1 Capacitors scheduled operation for 24 hours with PSO and GWO methods

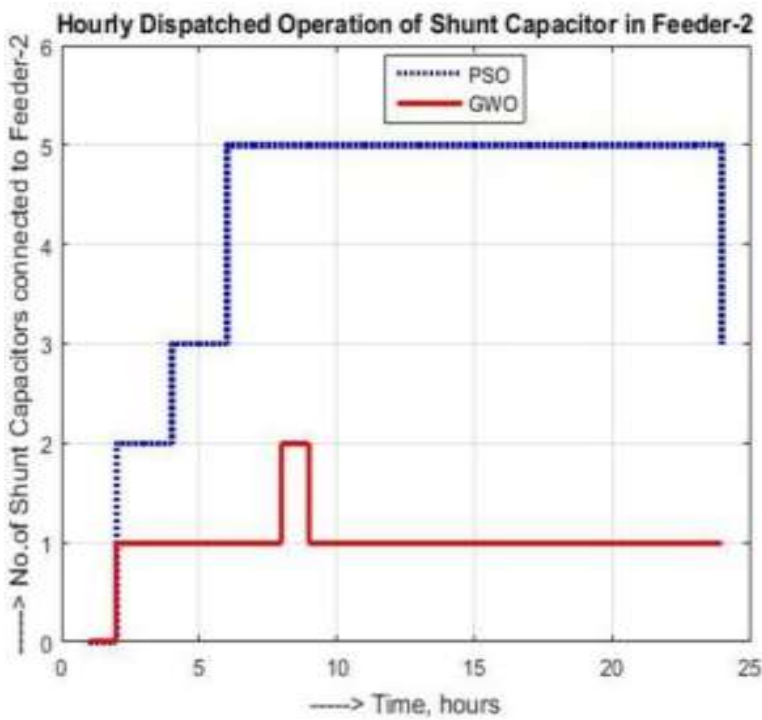

Figure 13. Feeder 2 Capacitors scheduled operation for 24 hours with PSO and GWO methods

Table 2. $10 \mathrm{kv}$ practical system results for Case 2

\begin{tabular}{ccccc}
\hline \multicolumn{5}{c}{ DG at Bus 5 on Feeder 2 } \\
\hline \multicolumn{2}{c}{ Control Methods } & CON & PSO & GWO \\
Power loss (MWh) & 12.92 & 12.17 & 11.03 \\
Number of & ULTC & 6 & 0 & 1 \\
Switching & SC & 10 & 10 & 0 \\
operations & F1C & 5 & 8 & 4 \\
of RPCDs & F2C & 3 & 4 & 6 \\
Fower loss $(\$)$ & 1033.60 & 973.840 & 882.760 \\
SSVF $(\%)$ & 23.36 & 14.72 & 11.63 \\
SOC $(\$)$ & 1480 & 1200 & 520 \\
\multicolumn{2}{c}{ Total Cost $(\$)$} & 2513.60 & 2173.84 & 1402.76 \\
\hline \multicolumn{2}{c}{$r$}
\end{tabular}


Table 4 illustrates reduction of power loss, SOC, SSVF, total cost and SON using proposed method as compared with conventional $(\mathrm{CON})$ and particle swarm optimization (PSO) methods. In all the cases proposed method reducing the objectives effectively as compared with CON and PSO.

Table 3. 10kv practical system results for Case3

\begin{tabular}{|c|c|c|c|c|}
\hline \multicolumn{5}{|c|}{ DG at Bus 5 on Feeder 3} \\
\hline \multicolumn{2}{|c|}{ Control Methods } & $\mathrm{CON}$ & PSO & GWO \\
\hline \multicolumn{2}{|c|}{ Power loss (MWh) } & 13.02 & 12.03 & 11.58 \\
\hline Number & ULTC & 4 & 2 & 1 \\
\hline of & SC & 10 & 1 & 5 \\
\hline Switching & $\mathrm{F} 1 \mathrm{C}$ & 6 & 11 & 1 \\
\hline operations & $\mathrm{F} 2 \mathrm{C}$ & 3 & 4 & 3 \\
\hline of RPCDs & F3C & 2 & 1 & 4 \\
\hline \multicolumn{2}{|c|}{ Power loss (\$) } & 1041.68 & 962.768 & 926.976 \\
\hline \multicolumn{2}{|c|}{$\operatorname{SSVF}(\%)$} & 23.39 & 14.53 & 11.19 \\
\hline \multicolumn{2}{|c|}{$\mathrm{SOC}(\$)$} & 1360 & 860 & 700 \\
\hline \multicolumn{2}{|c|}{ Total Cost $(\$)$} & 2401.68 & 1822.76 & 1626.97 \\
\hline
\end{tabular}

Table 4. 10kv practical system results comparision

\begin{tabular}{ccccccc}
\hline $\begin{array}{c}\text { DG } \\
\text { Location }\end{array}$ & \multicolumn{2}{c}{ Bus 5 } & \multicolumn{2}{c}{ Bus 8 } & \multicolumn{2}{c}{ Bus 14 } \\
\hline $\begin{array}{c}\text { GWO } \\
\text { Compared } \\
\text { with }\end{array}$ & CON & PSO & CON & PSO & CON & PSO \\
$\begin{array}{c}\text { Power } \\
\text { loss (\%) }\end{array}$ & 11.48 & 5.97 & 14.59 & 9.35 & 11.01 & 3.717 \\
SOC (\%) & 66.67 & 31.25 & 64.86 & 56.7 & 48.52 & 18.60 \\
SSVF (\%) & 52.59 & 24.91 & 50.23 & 20.9 & 52.15 & 23.00 \\
Total & 42.45 & 16.01 & 44.19 & 35.4 & 32.25 & 10.74 \\
Cost (\%) & & & & & & \\
SON (\%) & 58.33 & 28.57 & 53.84 & 52.00 & 44.00 & 26.31 \\
\hline
\end{tabular}

$$
\begin{aligned}
& \text { Powerloss }(\$)=80 * \text { Powerloss }(M W h) ; \\
& \operatorname{SOC}(\$)=\left(\begin{array}{l}
(80 \times U L T C)+(60 \times S C)+ \\
(40 \times(F 1 C+F 2 C+F 3 C))
\end{array}\right)
\end{aligned}
$$

$$
\text { Total } \cos t(\$)=\text { Powerloss }(\$)+\operatorname{SOC}(\$)
$$

\section{CONCLUSION}

This paper proposes a new method, in which reactive power of solar system is coordinated effectively along with ULTC and shunt capacitors. The following conclusions derived based on the results: Proposed method reduces power loss by $14.59 \%$ (maximum) and $11.01 \%$ (minimum) compared with conventional method, $9.35 \%$ (maximum) and 3.717\% (minimum) compared with PSO method. SOC reduced by $66.67 \%$ (maximum) and $48.52 \%$ (minimum) compared with conventional method, $31.25 \%$ (maximum) and $18.6 \%$ (minimum) compared with PSO method. SSVF reduced by $52.59 \%$ (maximum) and $50.23 \%$ (minimum) compared with conventional method, 24.91\% (maximum) and 20.9\% (minimum) compared with PSO method. Total cost reduced by $44.19 \%$ (maximum) and $32.25 \%$ (minimum) compared with conventional method, $35.4 \%$ (maximum) and $10.74 \%$ (minimum) compared with PSO method. SON reduced by $58.33 \%$ (maximum) and $44.0 \%$ (minimum) compared with conventional method, 52\% (maximum) and $26.31 \%$ (minimum) compared with PSO method. The proposed method effectively reduced the objective functions irrespective of solar system location.

\section{REFERENCES}

[1] H Jiayi, J Chuanwen, X Rong, “A review on distributed energy resources and micro grid,” Renew. Sustain. Energy Rev, vol.12, no.9,(2008),pp.2472-2483. https://doi.org/10.1016/j.rser.2007.06.004

[2] L Wang, D H Liang, A F Crossland, P.C. Taylor, D Jones, N S Wade, "Coordination of Multiple energy storage units in a low voltage distribution network," IEEE Transactions on Smart Grid, vol.6, no.6, pp.2906-2918, 2015. https://doi.10.1109/tsg.2015.2452579

[3] Ruey Hsun, L Chen Kuo, "Dispatch of main transformer ULTC and capacitors in a distribution system," IEEE Transactions on Power Delivery, vol. 16, no. 4, pp.625-630, 2001. https://doi.10.1109/61.956748

[4] J O Donnel, "Voltage management of networks with distributed generation," PhD thesis. Edinburgh \& U.K.; 2007.

[5] F A Vivan, "Voltage control and voltage stability of power distribution systems in the presence of distributed generation," PhD thesis. Sweden \& U.K.; 2008.

[6] F C Lu, Y Y Hsu., "Reactive power/voltage control in a distribution substation using dynamic programming," Proc. Inst. Elect. Eng., Gen., Trans., Dist., vol. 142, no. 6, pp. 639-645, 1995.

[7] F A Vivan, D Karlsson, "Combined local and remote voltage and reactive power control in the presence of induction machine distributed generation," IEEE Transactions on Power Systems, vol. 22, no.4, pp. 2003-2012, 2007. https://doi.10.1109/tpwrs.2007.907362

[8] F A Vivan, D Karlsson, "Voltage and reactive power control in systems with synchronous machine based distributed generation," IEEE Transactions on Power Delivery, vol. 23, no. 2, pp.1079-1087, 2008. https://doi.10.1109/tpwrd.2007.915870 
[9] C J Dent, L F Ochoa, G P Harrison, "Network distributed generation capacity analysis using OPF with voltage step constraints," IEEE Transactions on Power Systems, vol. 25, no. 1, pp.296-304, 2010. https://doi.10.1109/tpwrs.2009.2030424

[10] A R Ahmadi, T C Green, "Optimal power flow for autonomous regional active network management system," IEEE Power \& Energy Society General Meeting, pp.1-7, 2009. https://doi.10.1109/pes.2009.5275373

[11] W Sheng, K Y Liu, Y S Cheng, "A trust region SQP method for coordinated voltage control in smart distribution system," IEEE Transactions on Smart Grid, vol. 7, no. 1, pp. 381-391, 2016. https://doi.10.1109/tsg.2014.2376197

[12] H Li, F Li, Y Xu, D T Riyaz, J D Kueck, "Adaptive voltage control with distributed energy sources: Algorithm, theoretical analysis, simulation, and field test verification," IEEE Transactions on Power Systems, vol.25, no.3, pp.1638-1647, 2010.

[13] Y J Kim, S J Ahn, P I Hwang, P G Chan, S I Moon, "Coordinated control of a DG and voltage controlled devices using a dynamic programming algorithm,” IEEE Transactions on Power Systems, vol. 28, no. 1, pp.42-51. 2013, https://doi.10.1109/tpwrs.2012.2188819

[14] M. Sankaraiah, S.Suresh Reddy, M. Vijaya Kumar, "Particle Swarm Optimization based Reactive power Coordinated control of distributed generation and voltage controlled devices," The Journal of CPRI, vol. 13, no. 3, , pp. 447-454, 2017.

[15] H Li, F Li, Y Xu, D T Riyaz, J D Kueck, “Adaptive voltage control with distributed energy sources: Algorithm, theoretical analysis, simulation, and field test verification," IEEE Transactions on Power Systems, vol. 25, no. 3, pp. 1638-1647, 2010.

[16] Y J Kim, S J Ahn, P I Hwang, P G Chan, S I Moon. Coordinated control of a DG and voltage controlled devices using a dynamic programming algorithm. IEEE Transactions on Power Systems. 2013; 28(1): 42-51.

[17] W Sheng, K Y Liu, Y Liu, X Ye, H Kaiyuan. A reactive power coordination optimization method with renewable distributed generation based on improved harmony search. IET Generation, Transmission \& Distribution. 2016; 10(13): 3152-3162.

[18] M Sankaraiah, S Suresh reddy, M Vijaya kumar. Particle swarm optimization based reactive power coordinated control of distributed generation and voltage controlled devices. The Journal of CPRI, vol. 13, npo. 3, pp. 447-454. 2017.

[19] M Sankaraiah, S Suresh reddy, M Vijaya kumar, "GWO based optimal reactive power coordination of DFIG, ULTC and capacitors," Indonesian Journal of Electrical Engineering \& Control Science, vol. 11, no. 3, pp. 805-812, 2018.

[20] Manish Kumar, Ashwani Kumar, K S Sandhu, "PV-WT based distribution generator location minimizing transmission loss in pool/Bilateral electricity market model," Procedia Technology, vol. 25, no. 1, pp.692-701. https://doi.org/10.1016/j.protcy.2016.08.162

[21] Subhadarshi Sarkar. Minding the P's and Q's: Real and reactive power assessment of hybrid energy conversion systems with wind and solar resources. PhD thesis, Iowa state university \& Ames, 2013.

[22] D Goldberg, "Genetic Algorithms in optimization search and machine learning," Addison Wesley, New York. 1995.

[23] R Storn, K Price. "Differential evolution- a simple and efficient heuristic for global optimization over continuous spaces". Journal of global optimization. vol. 11, no. 4, pp. 341-359, 1997. https://doi.org/10.1023/A:1008202821328

[24] X Yao, Y Liu, G Lin., "Evolutionary programming made faster". IEEE Transactions on Evolutionary Computation, vol. 3, no. 2, pp.82-102, 1999. https://doi.10.1109/4235.771163

[25] D Fogel, “Artificial Intelligence through simulated evolution,” Wiley-IEEE press 2009.

[26] B Webster, P J Bernhard, "A Local search optimization algorithm based on natural principles of gravitation. International Conference on Information and Knowledge Engineering," Las Vegas. USA. 2003, 255-261.

[27] O K Erol, I Eksin, "A new optimization method: big bang-big crunch," Advances in Engineering Software, vol. 37, no. 2, pp. 106-111, 2006. https://doi.10.1016/j.advengsoft.2005.04.005

[28] E Rashedi, H Nezamabadi Pour, S Saryazdi. "GSA: a gravitational search algorithm. Information sciences", Journal of Intelligent Learning Systems and Applications, vol.179, no.13, (2009), pp.2232-2248. https://doi:10.1016/j.ins.2009.03.004.

[29] B Alatas. "ACROA: Artificial Chemical Reaction Optimization Algorithm for global optimization Expert Systems with Applications”, International Journals of Systems Science, vol.38, no.2, (2011), pp. 13170-13180. https://doi:10.1080/00207721.2018.1432780

[30] M Roth, "Termite: A swarm intelligent routing algorithm for mobile wireless ad-hoc networks," Wireless Intelligent Systems Laboratory, pp. 1-31, New York, 2005.

[31] X Lu, Y Zhou, "A novel global convergence algorithm: bee collecting pollen algorithm. International Conference on Advanced Intelligent Computing Theories and Applications," Springer, Shanghai, China, 2008, pp.518-525.

[32] A Mucherino, O Seref. "Monkey search: a novel met heuristic search for global optimization. AIP conference proceedings". Gainesville. Florida, 2007, pp.162-173.

[33] P C Pinto, T A Runkler, J M Sousa. "Wasp swarm algorithm for dynamic max- sat problems. 8th International conference on Adaptive and Natural Computing algorithms", Springer, 2007, pp.350-357.

[34] S Mirjalili, S M Mirjalili, A Lewis. "Grey Wolf Optimizer". Advances in Engineering Software, vol. 69, no. 1, 2014. pp.46-61.https://aip.scitation.org/doi/10.1063/1.4973255 


\section{BIOGRAPHIES OF AUTHORS}

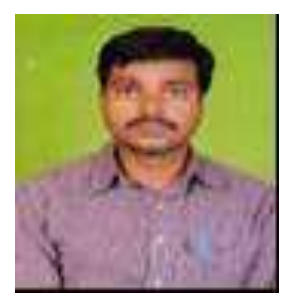

M.Sankaraiah has obtained his B.Tech degree from S.V.University and M.Tech degree from N.I.T,Calicut. He has 10 years of teaching experience. He published 8 research papers at International level. He is presently a research scholar at JNTUA, Anantapur,A.P. He is working in the area of Distributed Generation, FACTS Controllers\& Algorithms.

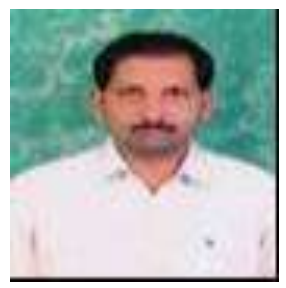

Dr.S.Suresh Reddy has obtained his M.Tech degree and Ph.D degree from JNTU,Hyderabad. He has 13 years of teaching experience. He published 15 research papers at National and International level. Hisresearch area is FACTS Controllers and Distributed Generation.

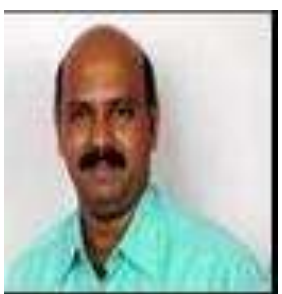

Prof.M.Vijaya Kumar has obtained his M.Tech from NIT,Warangal and Ph.D from JNTU,Hyderabad. He has 23 years of teaching experience. He has published 52 research papers at National and International level. His research area is Power Quality Improvement in Power Systems. 